\title{
Effect of denosumab on bone mineral density and biochemical markers of bone turnover: 8-year results of a phase 2 clinical trial
}

\author{
M. R. McClung • E. M. Lewiecki • M. L. Geller \\ M. A. Bolognese $\cdot$ M. Peacock • R. L. Weinstein \\ B. Ding • E. Rockabrand $\cdot$ R. B. Wagman $・$ P. D. Miller
}

Received: 12 March 2012 / Accepted: 30 April 2012 / Published online: 10 July 2012

(C) The Author(s) 2012. This article is published with open access at Springerlink.com

\begin{abstract}
Summary In a phase 2 study, continued denosumab treatment for up to 8 years was associated with continued gains in bone mineral density and persistent reductions in bone turnover markers. Denosumab treatment was well tolerated throughout the 8-year study.

Introduction The purpose of this study is to present the effects of 8 years of continued denosumab treatment on bone mineral density (BMD) and bone turnover markers (BTM) from a phase 2 study.

Methods In the 4-year parent study, postmenopausal women with low BMD were randomized to receive placebo, alendronate, or denosumab. After 2 years, subjects were reallocated to continue, discontinue, or discontinue and reinitiate denosumab; discontinue alendronate; or maintain placebo
\end{abstract}

\footnotetext{
M. R. McClung ( $\bowtie)$

Oregon Osteoporosis Center,

5050 NE Hoyt Street, Suite 626,

Portland, OR 97213, USA

e-mail: mmcclung@orost.com
}

\section{E. M. Lewiecki}

New Mexico Clinical Research \& Osteoporosis Center,

Albuquerque, NM, USA

e-mail: Lewiecki@aol.com

M. L. Geller • B. Ding • E. Rockabrand • R. B. Wagman

Amgen Inc.,

Thousand Oaks, CA, USA

M. L. Geller

e-mail: mgeller@amgen.com

B. Ding

e-mail: bding@amgen.com

E. Rockabrand

e-mail: erockabr@amgen.com

R. B. Wagman

e-mail: rwagman@amgen.com for two more years. The parent study was then extended for 4 years where all subjects received denosumab.

Results Of the 262 subjects who completed the parent study, 200 enrolled in the extension, and of these, 138 completed the extension. For the subjects who received 8 years of continued denosumab treatment, BMD at the lumbar spine $(N=88)$ and total hip $(N=87)$ increased by 16.5 and $6.8 \%$, respectively, compared with their parent study baseline, and by 5.7 and $1.8 \%$, respectively, compared with their extension study baseline. For the 12 subjects in the original placebo group, 4 years of denosumab resulted in BMD gains comparable with those observed during the 4 years of denosumab in the parent study. Reductions in BTM were sustained over the course of continued denosumab treatment.
M. Peacock

Indiana University School of Medicine,

Indianapolis, IN, USA

e-mail: mpeacock@iupui.edu

R. L. Weinstein

Diablo Clinical Research, Inc.,

Walnut Creek, CA, USA

e-mail: rweinstein@diabloclinical.com

P. D. Miller

Colorado Center for Bone Research,

Lakewood, CO, USA

e-mail: MillerCCBR@aol.com 
Reductions also were observed when the placebo group transitioned to denosumab. Adverse event profile was consistent with previous reports and an aging cohort. Conclusion Continued denosumab treatment for 8 years was associated with progressive gains in BMD, persistent reductions in BTM, and was well tolerated.

Keywords Bone mineral density $\cdot$ Bone turnover markers . Denosumab $\cdot$ Osteoporosis $\cdot$ RANK ligand

\section{Introduction}

Osteoporosis is a chronic disorder of skeletal fragility and impaired bone strength due to progressive loss of bone mass, resulting in thinning and increased porosity of cortical bone and disruption of trabecular architecture. These changes are the result of an imbalance in bone remodeling where bone resorption exceeds bone formation. The RANK/ RANK ligand pathway is an important modulator of osteoclast activity [1-6]. Increased production of RANK ligand is implicated as a cause of increased bone remodeling in postmenopausal women $[7,8]$.

Denosumab (Prolia ${ }^{\circledR}$, Amgen Inc., Thousand Oaks, CA) is a fully human IgG2 antibody that binds to RANK ligand with very high specificity [9]. By preventing the interaction of RANK ligand to its receptor RANK, denosumab is a potent anti-resorptive agent, decreasing the formation, function, and survival of osteoclasts [2-5]. We have previously demonstrated that denosumab treatment of postmenopausal women with low bone mass reduces bone remodeling and increases bone mineral density (BMD) [10-13]. In women with postmenopausal osteoporosis, denosumab therapy significantly reduced the risk of new vertebral, hip, and nonvertebral fractures at 3 years compared with placebo [14]. This agent has received regulatory approval in many countries for treating women with postmenopausal osteoporosis at increased risk or high risk for fracture.

Anti-resorptive agents, including denosumab, prevent the progression of bone loss and improve bone strength but do not restore trabecular architecture or cure osteoporosis. The salutary effects of denosumab on bone turnover and BMD resolve quickly upon discontinuation of therapy [12], meaning that continued, long-term therapy with denosumab is required to sustain the anti-fracture benefit. The results of the 4-year phase 2 dose-ranging study along with a 2-year interim analysis of the extension representing a total of 6 years of denosumab therapy have previously been reported [10-13]. Here, we report the final results of the 4-year extension of the phase 2 study, focusing on the skeletal effects, and safety and tolerability of denosumab in subjects who received continued denosumab therapy for a total of 8 years.

\section{Materials and methods}

The details of both the original 4-year phase 2 study and the extension study have already been published [10-13]. Those methods are summarized below.

Study design

The open-label, 4-year study extension was performed in 23 centers in the USA. An institutional review board reviewed and approved the study protocol at each center, and all women provided written informed consent. The study was performed in compliance with the FDA, International Conference on Harmonisation (ICH) Good Clinical Practice guidelines, and the World Medical Association Declaration of Helsinki principles.

Subjects

The 412 women enrolled in the parent phase 2 study were postmenopausal, $\leq 80$ years old, and had a BMD T-score between -1.8 and -4.0 for the lumbar spine, or between -1.8 and -3.5 for either the total hip or femoral neck. The subjects who agreed to participate in the extension study had to have successfully completed the parent study, including the end-of-study visit at month 48. Subjects were excluded if, during the parent study, they had experienced severe and/or serious adverse events or abnormal laboratory results thought to be related to denosumab; discontinued investigational product due to protocol-specified BMD decrease during the study; missed two or more scheduled administrations of investigational product during year 3 or 4; used any bone active drugs; or developed a disease known to affect bone metabolism.

\section{Efficacy outcomes}

Details of the assessment of BMD by dual-energy x-ray absorptiometry (DXA) and the collection and measurements of markers of bone turnover have been described previously $[11,12]$. During the extension study, DXA scans of the lumbar spine, proximal femur, and one-third radius were measured annually and were analyzed centrally. Serum bone turnover markers, C-telopeptide of type 1 collagen (CTX) and bone-specific alkaline phosphatase (BSAP), were collected after an overnight fast and before the next dose of denosumab at the extension study baseline (end of year 4 of the parent study), and at 6-monthly intervals throughout the study extension.

Reports of adverse events were collected at each visit including information about new clinical fractures. Clinical laboratory measurements for safety assessment included standard hematology and serum chemistries that 
were performed at every visit in the study extension through month 24 (chemistry performed also at month 25 or month 1 of year 3 ) and at the final visit at month 48. A central laboratory, Covance Laboratories (Indianapolis, IN) was used to analyze all hematology and serum chemistry. Anti-denosumab binding antibody titers were drawn at entry, month 1,6 , and 12 , and then yearly throughout the extension study. Antibody evaluation used a validated electrochemiluminescent immunoassay, and a cell-based assay was used to screen positive samples, as previously described [10-12].

\section{Treatments}

Treatment groups in the parent study and the extension study are presented in Fig. 1. The 200 subjects in the extension study all received open-label denosumab $60 \mathrm{mg}$ subcutaneously every 6 months (Q6M) with the last dose administered at month 42 of the extension study. Here, our efficacy findings focus on subjects who received 8 years of continued denosumab in the parent and extension studies, and those who received placebo for 4 years in the parent study followed by 4 years of denosumab in the extension study. Although subjects in the continued therapy group received different regimens of denosumab during the parent study, they were treated as a single group in the 4-year extension study. All subjects were included in the safety analyses regardless of their previous treatment groups (continued denosumab, intermittent denosumab [retreatment and off-treatment], placebo, or alendronate). All subjects were instructed to take daily oral supplements of calcium $(\geq 500 \mathrm{mg})$ and vitamin $\mathrm{D}(\geq 400 \mathrm{IU})$.

\section{Statistical methods}

All analyses were descriptive. No hypothesis testing was performed since the primary objective of the study was long-term safety of denosumab treatment. Sample size was based on the number of subjects who completed the parent study and were willing to participate in the extension study. Summary statistics for continuous endpoints included mean, standard deviation, Q1, median, and Q3 and the number of nonmissing observations. For categorical endpoints, frequencies and percentages were used.

Efficacy analysis included all subjects enrolled in the extension study and had evaluable data for the time point of interest. Percentage changes in BMD at the lumbar spine, total hip, femoral neck, and one-third radius over time were summarized using an analysis of covariance (ANCOVA) model with the treatment groups as the main effect, and geographical location and the parent or extension study baseline BMD as covariates. The least-squared means (LSM) and $95 \%$ confidence intervals (CI) of percent changes in BMD up to 8 years are presented. Because the BTM values were skewed, medians and interquartile ranges (1st quartile [Q1] to 3rd quartile [Q3]) were calculated.

Safety analysis included all subjects who had received one or more doses of denosumab during the extension study.
Fig. 1 Study design of the 4year parent dose-ranging study with the different treatment regimens at months 24 and 48 , and the 4-year extension study with all subjects receiving open-label denosumab $60 \mathrm{mg}$ every 6 months. $n=$ number of subjects who enrolled in the parent and extension study and those that completed each study

\begin{tabular}{|c|c|c|c|c|c|}
\hline & Parer & nt Study & & Extension Stuc & \\
\hline Study Month & 12 & 24 & 36 & 72 & 96 \\
\hline Continued Treatment & \begin{tabular}{|c|} 
Denosumab \\
6 or $14 \mathrm{mg} \mathrm{Q3M}$ \\
14,60 , or $100 \mathrm{mg}$ Q6M
\end{tabular} & $\begin{array}{l}\text { Denos } \\
60 \mathrm{mg}\end{array}$ & $\begin{array}{l}\text { sumab } \\
\text { Q6M }\end{array}$ & $\begin{array}{l}\text { Denosumab } \\
60 \mathrm{mg} \text { Q6M }\end{array}$ & \\
\hline & $=231$ & & 153 & & 90 \\
\hline Retreatment & $\begin{array}{l}\text { Denosumab } \\
30 \mathrm{mg} \text { Q3M }\end{array}$ & \begin{tabular}{|l} 
Discontinued \\
Denosumab
\end{tabular} & $\begin{array}{l}\text { Denosumab } \\
60 \mathrm{mg} \text { Q6M }\end{array}$ & $\begin{array}{l}\text { Denosumab } \\
60 \mathrm{mg} \mathrm{Q6M}\end{array}$ & \\
\hline & $=41$ & & & & 10 \\
\hline Off-treatment & $\begin{array}{r}\text { Denosumab } \\
210 \mathrm{mg} \mathrm{Q6M}\end{array}$ & Discontinued & Denosumab & $\begin{array}{l}\text { Denosumab } \\
60 \mathrm{mg} \text { Q6M }\end{array}$ & \\
\hline & $=47$ & & & & 12 \\
\hline Alendronate & $\begin{array}{l}\text { Alendronate } \\
70 \mathrm{mg} \mathrm{QW}\end{array}$ & Discontinued & Alendronate & $\begin{array}{l}\text { Denosumab } \\
60 \mathrm{mg} \mathrm{Q6M}\end{array}$ & \\
\hline & $=47$ & & & & 14 \\
\hline Placebo & Placebo & Plac & cebo & $\begin{array}{l}\text { Denosumab } \\
60 \mathrm{mg} \mathrm{Q6M}\end{array}$ & \\
\hline
\end{tabular}




\section{Results}

Subjects

Baseline demographics for both the parent and extension studies have been reported previously and are summarized in Table 1 $[11,12]$. One hundred thirty-eight (69\%) of the 200 subjects who enrolled in the extension study completed the 4-year study (8 years since parent baseline; Fig. 1). The reasons for discontinuation for the 62 subjects who did not complete the extension study included withdrawal of consent (22), adverse event (8), death (8), lost to follow-up (5), administrative decision (3), and other (16). One hundred twenty-four (62\%) had received continued denosumab treatment during the parent study. Of these, $90(73 \%)$ completed the 8-year study assessment.

\section{BMD and BTM assessments}

\section{Continued denosumab treatment cohort}

For the subjects who received 8 years of continued denosumab treatment and had evaluable data, BMD at the lumbar spine and total hip significantly increased during the 4 years of the extension study, while the BMD at the one-third radius remained stable (Fig. 2). Compared with the parent study baseline, eight continued years of denosumab treatment was associated with mean BMD changes of $16.5,6.8$, and $1.3 \%$ at the lumbar spine, total hip, and one-third radius, respectively (Fig. 2), and $6.8 \%$ at the femoral neck (data not shown). From the extension study baseline, BMD increased at the lumbar spine by $5.7 \%$ (Fig. 2a), total hip by $1.8 \%$ (Fig. 2b), one-third radius by $0.8 \%$ (Fig. 2c), and femoral neck by $2.3 \%$ on average (data not shown). At the end of year 8 , the serum CTX and BSAP remained below parent study baseline with median reductions of 65 and $44 \%$, respectively (Fig. 3). The levels of reduction in both CTX and BSAP at the end of the dose interval were similar at all time points in the study extension.
Previous placebo cohort

In the subjects who received placebo during the 4-year parent study, BMD increased at the lumbar spine, total hip, and femoral neck with 4 years of denosumab treatment in the extension study. From the extension study baseline, BMD increased by $11.9 \%$ at the lumbar spine (Fig. 2a), $5.6 \%$ at the total hip (Fig. 2b), and $4.0 \%$ at the femoral neck on average (data not shown). BMD at the one-third radius did not change during the extension study (Fig. 2c). Subjects from the previous placebo group also responded to denosumab treatment with reductions in CTX and BSAP. Median values of both markers decreased to levels observed in the subjects who had received continued denosumab therapy (Fig. 3).

\section{Other treatment cohorts}

Independent of previous treatment in the parent study, BMD and BTM responses in the other treatment groups (retreatment, off-treatment, and alendronate) were similar to the continued treatment group (data not shown). BTM reductions in these smaller cohorts were similar to the continued denosumab treatment group and remained within the premenopausal reference ranges throughout the extension study.

\section{Safety}

All subjects in the study extension received one or more doses of denosumab, and 142 subjects (71\%) received all 8 doses of denosumab. One hundred eighty-four subjects $(92 \%)$ reported one or more adverse events. The 4 most frequent adverse events were upper respiratory infection (22.5\%), arthralgia (18.5\%), back pain (12.5\%), and hypertension (12.5\%; Table 2 ), findings that were consistent with what was reported during the 4 years of treatment with denosumab or placebo in the parent study and the first

Table 1 Subject demographics and characteristics at baseline in parent and extension studies

\begin{tabular}{|c|c|c|c|}
\hline & \multicolumn{2}{|l|}{ Years 1-4 parent study } & \multirow{2}{*}{$\frac{\text { Years 5-8 extension study }}{\text { Denosumab }(N=200)}$} \\
\hline & All subjects $(N=412)$ & Denosumab $(N=319)$ & \\
\hline Age, years & $62.5(8.1)$ & $62.3(8.0)$ & $66.1(7.7)$ \\
\hline Lumbar spine BMD T-score & $-2.14(0.78)$ & $-2.14(0.77)$ & $-1.55(0.96)$ \\
\hline Total hip BMD T-score & $-1.44(0.71)$ & $-1.42(0.69)$ & $-1.21(0.73)$ \\
\hline One-third BMD T-score & $-1.48(1.21)$ & $-1.48(1.18)$ & $-1.35(1.19)$ \\
\hline Albumin-adjusted calcium, mg/dL & $9.77(0.37)$ & $9.77(0.37)$ & $9.86(0.37)$ \\
\hline Creatinine, $\mathrm{mg} / \mathrm{dL}$ & $0.76(0.15)$ & $0.76(0.15)$ & $0.83(0.16)$ \\
\hline Subjects who completed, $n(\%)$ & $262(64 \%)$ & $203(64 \%)$ & $138(69 \%)$ \\
\hline
\end{tabular}

Values are mean (SD) unless indicated otherwise 
Fig. 2 Effect of 8 years of continued denosumab treatment on BMD at the a lumbar spine, b total hip, and $\mathbf{c}$ one-third radius. BMD values are shown as percent change from parent study baseline (LSM+95\% CI based on ANCOVA models adjusting for geographical location and parent study baseline BMD values). Gray boxes indicate the original 4-year parent study. Numbers shown at each time point reflect the number of subjects enrolled in the extension study with observed data at the selected time points of interest a. Lumbar Spine

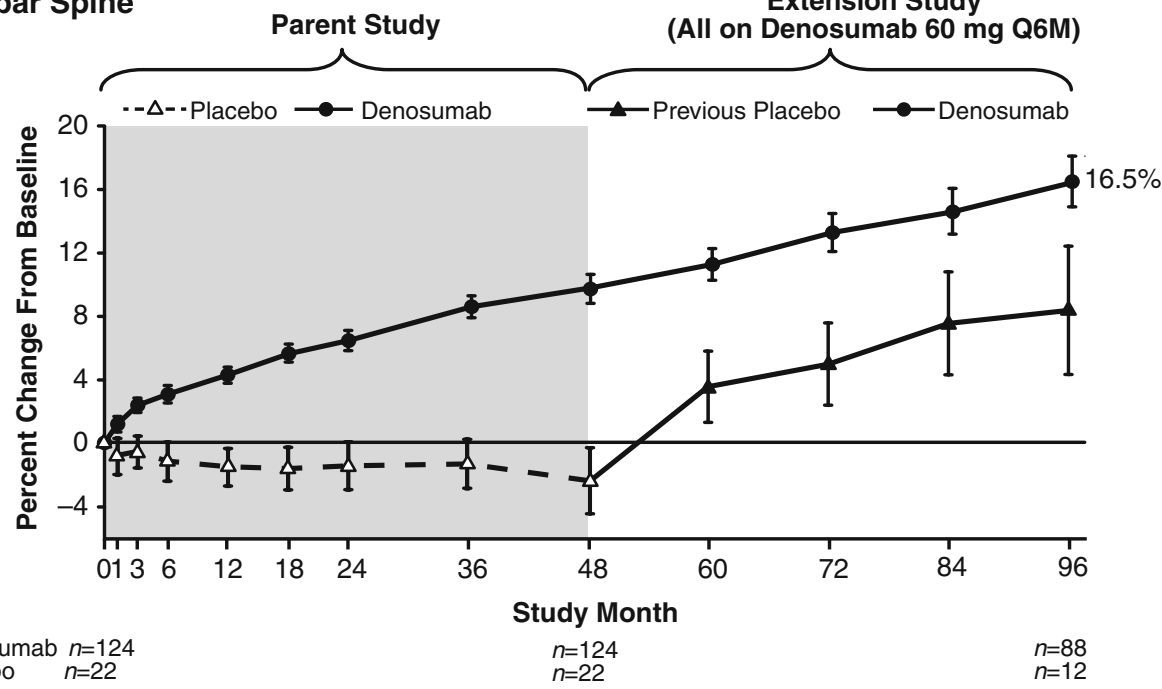

b. Total Hip

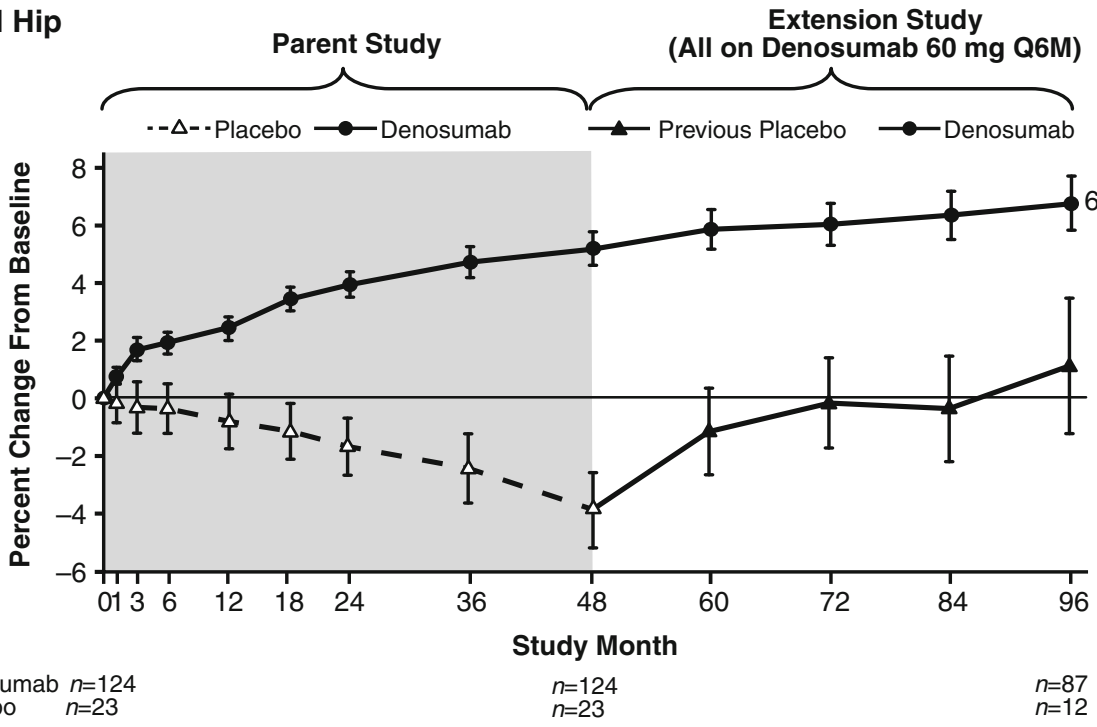

c. One-third Radius

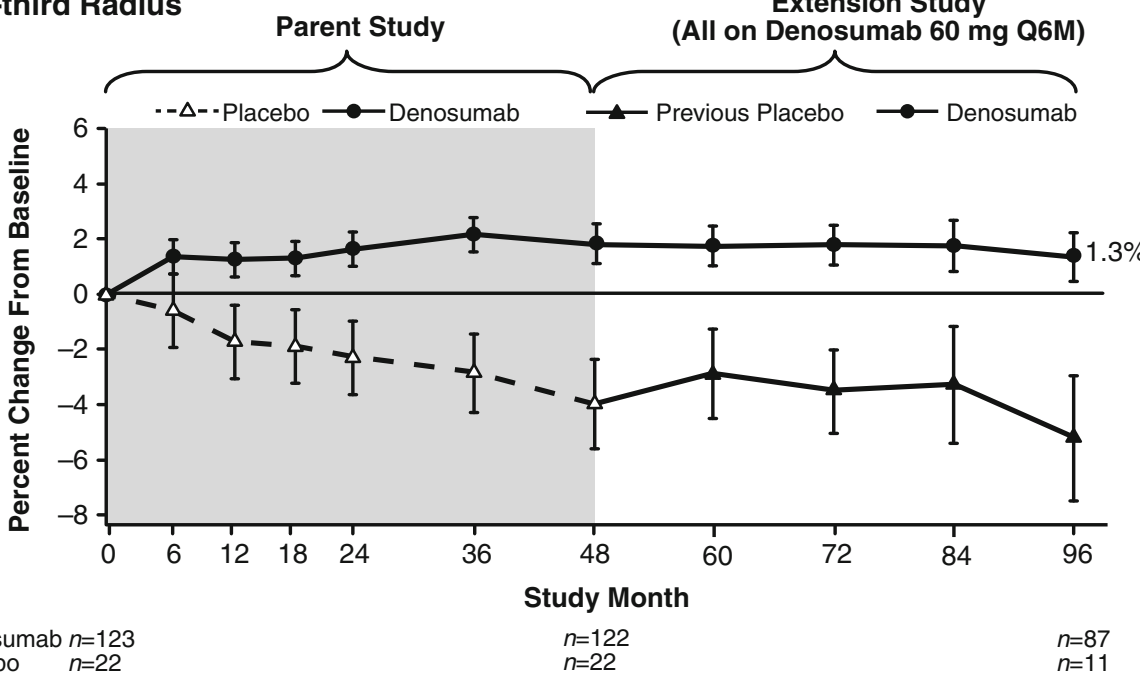


Fig. 3 Effect of 8 years of continued denosumab treatment on levels of a serum CTX and $\mathbf{b}$ BSAP. Bone turnover markers are shown as actual values (medians with Q1 to Q3 interquartile ranges). Gray boxes indicate the original 4year parent study. Numbers shown at each time point reflect the number of subjects enrolled in the extension study with observed data at the selected time points of interest. Asterisk A calibration discrepancy at the central laboratory may have led to BSAP results in some individual samples to be falsely elevated by up to $14 \%$ at months 90 and 96

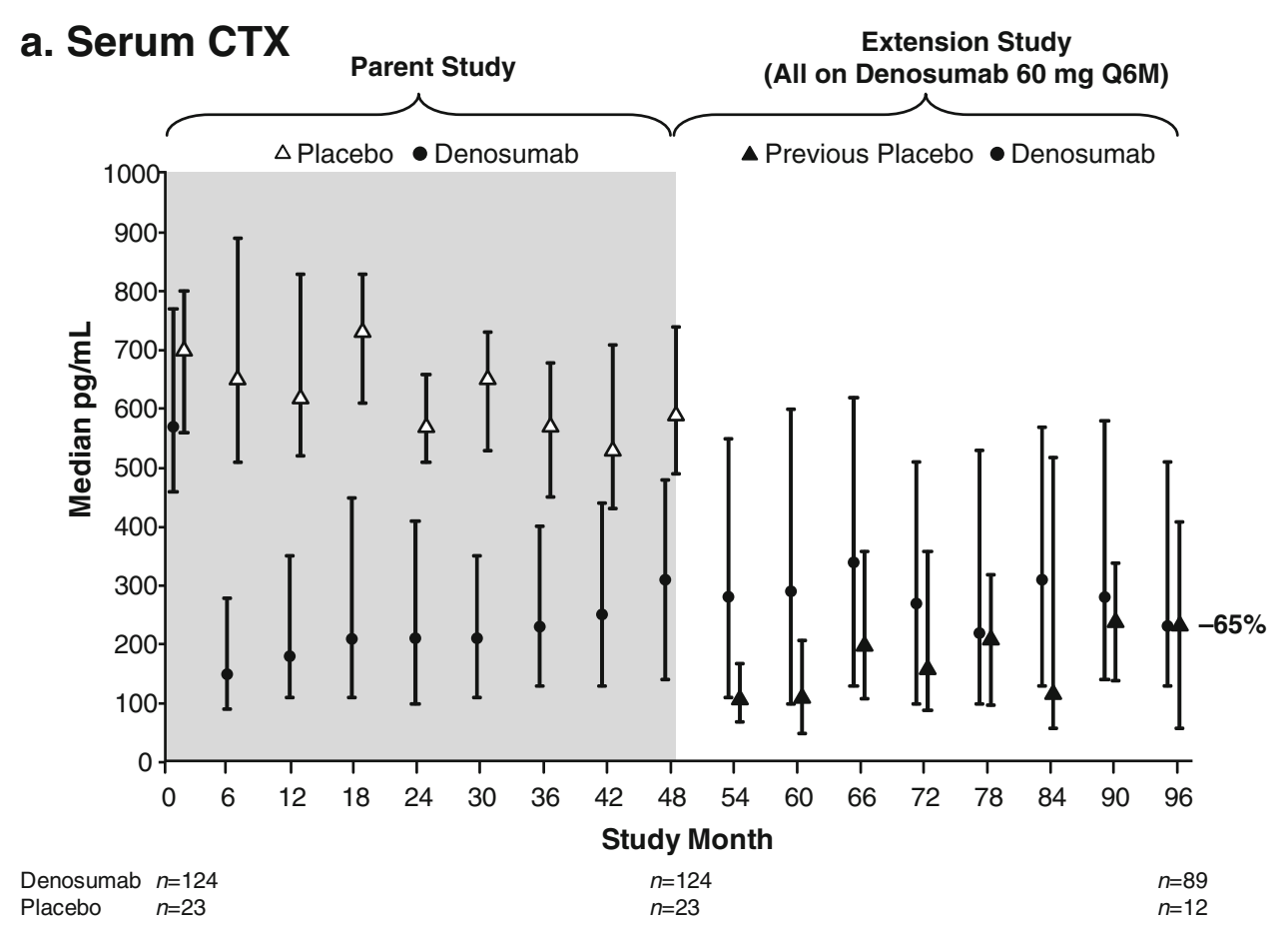

b. BSAP

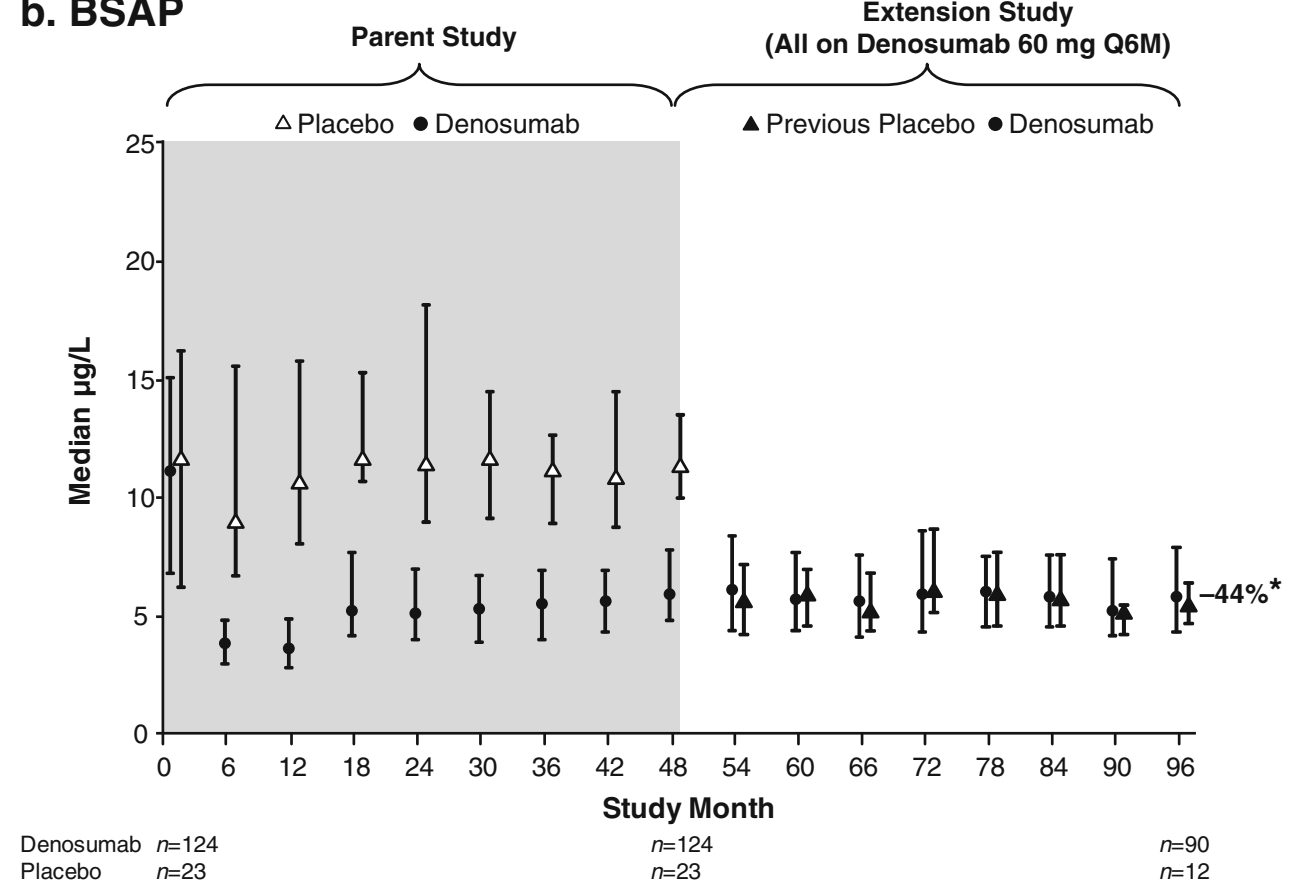

2 years of the extension study. Three subjects (1.5\%) experienced non-serious skin infections, and seven subjects (3.5\%) reported other skin adverse events (eczema [3] and contact dermatitis [4]); none of these events were related to the injection site. Thirty-two subjects (16\%) experienced neoplasms, and of these subjects, 24 subjects (12\%) experienced malignant or unspecified neoplasms (Table 2). No difference was noted between the incidence of malignant or unspecified neoplasms during the 4-year extension study period in the subjects who received continued denosumab therapy for 8 years $(15.3 \%)$ and those who received placebo for 4 years followed by denosumab treatment for 4 years $(13.0 \%)$.

Serious adverse events occurred in 45 subjects $(22.5 \%$; Table 2). Seven subjects (3.5\%) experienced serious adverse events of infection associated with hospitalization including respiratory infection or pneumonia (5), endocarditis and staphylococcal bacteremia (1), and diverticulitis (1). Eight subjects died during the extension study and another subject died after 
Table 2 Adverse event summary

Adverse events overall

\begin{tabular}{ll}
\hline & Years 5-8 extension study \\
\hline Event, \% $(n)$ & Denosumab $(N=200)$ \\
Any adverse event & $92.0 \%(184)$ \\
Infections & $60.5 \%(121)$ \\
Malignant or unspecified neoplasms ${ }^{\mathrm{a}}$ & $12.0 \%(24)$ \\
Osteoporotic fractures & $4.5 \%(9)$ \\
Serious adverse events & $22.5 \%(45)$ \\
$\quad$ Hospitalized infections & $3.5 \%(7)$ \\
Withdrawals due to adverse event & $5.0 \%(10)$ \\
Deaths & $4.5 \%(9)$ \\
& \\
Adverse events occurring in $\geq 10 \%$ & \\
of subjects, \% $(n)$ & \\
Upper respiratory infection & $22.5 \%(45)$ \\
Arthralgia & $18.5 \%(37)$ \\
Back pain & $12.5 \%(25)$ \\
Hypertension & $12.5 \%(25)$ \\
Pain in extremity & $11.5 \%(23)$ \\
Sinusitis & $11.5 \%(23)$ \\
Cataract & $11.0 \%(22)$ \\
Urinary tract infection & $10.0 \%(20)$ \\
\hline
\end{tabular}

$N=$ all subjects who received one or more doses of study drug; $n=$ number of subjects reporting one or more events

${ }^{a}$ During years 5 to 8,3 of the 23 subjects ( $13.0 \%$ ) who had previously received placebo treatment developed a neoplasm ( 2 with basal cell carcinoma and 1 with non-small cell lung cancer). Nineteen of the 124 subjects $(15.3 \%)$ who received continued denosumab therapy for 8 years had a neoplasm ( 7 with basal cell carcinoma, 1 with basal cell carcinoma and squamous cell cancer of the skin, 1 with bone neoplasm, hepatic neoplasm, and lung neoplasm, 2 with lung neoplasm, 2 with breast cancer, and 1 each with, Bowen's disease, or cancer or neoplasm of the colon, endometrium, ovary, pancreas, and thyroid). Two of the 17 subjects $(11.8 \%)$ who received $210 \mathrm{mg}$ denosumab during years 1 to 2 and placebo treatment during years 3 to 4 developed a neoplasm ( 1 with basal cell carcinoma and 1 with non-Hodgkin's lymphoma)

completion of the study from an adverse event that had occurred during the study: one each from cardiac arrest, cardiac failure, coronary heart disease, chronic obstructive pulmonary disease, malignant hepatic neoplasm, metastatic ovarian cancer, pancreatic carcinoma, non-small cell lung cancer, and from an unknown cause.

Nine subjects $(4.5 \%)$ sustained one or more osteoporotic fracture during the 4-year extension study. There were no reports of atypical femur fracture, delayed fracture healing, or fracture non-union. No case of osteonecrosis of the jaw (ONJ) was reported.

No unexpected trends in hematology or blood chemistries were observed as previously reported [13]. No adverse events of hypocalcemia were reported. No subject developed antibodies to denosumab during the extension study.

\section{Discussion}

By inhibiting the effects of RANK ligand on osteoclast proliferation and activity, denosumab is a potent inhibitor of bone turnover. Because sustained therapy with denosumab is thought to be necessary to achieve persistent antifracture therapy, experience with long-term therapy is important. These data from the phase 2 study demonstrate that the effects of denosumab on biochemical indices of bone remodeling persisted over 8 years of therapy, and long-term use of denosumab did not result in further inhibition of bone metabolism. Denosumab induced continued increases in BMD by DXA at the lumbar spine and total hip over the 8 -year treatment period, with the final changes from baseline being $16.5 \%$ at the lumbar spine and $6.8 \%$ at the total hip. A similar pattern of progressive increase in spine BMD with DXA has been observed over 10 years with alendronate and 7 years with risedronate treatment, although the magnitude of the response with denosumab appears to be greater than with those anti-resorptive agents $[15,16]$. However, the effect of denosumab on BMD at the proximal femur appears to be different than the responses to other anti-resorptive drugs. Total hip and femoral neck BMD increased progressively over the entire 8 -year treatment interval whereas these values have been observed to plateau after an initial increase with bisphosphonates. A continued increase in hip BMD has also been observed over 5 years of denosumab treatment in the much larger cohort of the pivotal phase 3 fracture study extension for the FREEDOM study [17]. Several mechanisms could possibly explain the progressive salutary effect of denosumab on hip BMD and the possible difference in response compared with other therapies. Denosumab is a more potent inhibitor of bone resorption than oral bisphosphonates [11, 18]. Moreover, unlike the response to oral bisphosphonate therapy, the inhibition of bone resorption with denosumab is dynamic, with maximal effect occurring shortly after dosing followed by gradual release of the inhibition over the 6-month interval before the next dose $[10,18]$. Both of these effects could result in a more positive balance in bone turnover than occurs with other agents.

The progressive increases in proximal femur BMD were not observed by DXA in the radius, another site of predominately cortical bone, where BMD remained stable but did not increase with long-term denosumab treatment. However, using the more sophisticated imaging techniques of quantitative computed tomography (QCT) and high-performance peripheral QCT, denosumab therapy has been associated with increased cortical bone mineral content, increased cortical thickness, and improved estimated strength in the radius and tibia $[19,20]$. Denosumab decreased porosity in the cortical bone (rib, tibia) of non-human primates to a greater degree than with 
bisphosphonate therapy [21]. This effect is also very different from the cortical response to teriparatide therapy with which cortical porosity increased and cortical BMD of the proximal femur decreased [22, 23].

This small phase 2 study and its extension were not designed with adequate statistical power to determine association between BMD changes with long-term denosumab with improved effectiveness through reduction in fracture risk. No study has adequately evaluated the pattern of hip or nonvertebral fracture risk reduction over time. By comparing the annual incidence of nonvertebral fractures with long-term therapy (beyond 5 years) with that which was observed during the first 3 years of treatment, the FREEDOM extension study may provide the opportunity to observe whether the continued effects on hip BMD and cortical bone result in progressively better protection from hip and nonvertebral fractures with long-term therapy.

Our report provides modest insight into the safety and tolerability of denosumab therapy over 8 years. Although safety of a treatment cannot be evaluated in such a small cohort of subjects, no untoward effects with long-term denosumab therapy were noted. The occurrences of adverse events, serious adverse events, and deaths during years 5 to 8 of therapy were similar to those observed during the first 4 years of treatment with denosumab and were consistent with the advancing age of the study subjects. No evidence of unwanted skeletal effects of sustained inhibition of bone metabolism (ONJ, atypical femoral fractures, or impaired fracture healing) was observed, and there was no signal of immune dysfunction.

Despite the length of our study, it has important limitations. No placebo group exists after 4 years. This and the small number of subjects completing the full 8year course of denosumab therapy markedly limit the assessment of safety. While no clinical trial can identify rare side effects of a therapy or adequately prove that a drug is safe, the FREEDOM extension trial, by following 2 large cohorts for totals of 7 and 10 years, will help in further characterizing the long-term safety of denosumab over time.

In conclusion, these final results of a phase 2 study and its extension demonstrate sustained effects of denosumab therapy on bone remodeling and progressive, substantial increases in BMD over 8 years in postmenopausal women with low bone mass. Treatment was well tolerated, and the adverse event profile was consistent with an aging population and was similar to what has been reported previously. Long-term treatment with denosumab is an effective treatment option for the management of postmenopausal osteoporosis.

Acknowledgments We thank all investigators involved in this study and Amgen Inc. sponsored this study.
Funding source This study was funded by Amgen Inc., Thousand Oaks, CA, 91320, USA.

Conflicts of interest MR McClung: Research grants from Amgen Inc., Eli Lilly, Merck, Novartis, and Procter \& Gamble. Consultant and/or on speaker boards for Amgen Inc., Eli Lilly, Merck, Novartis, Procter \& Gamble, and sanofi-aventis.

EM Lewiecki: Research support from Amgen Inc., Eli Lilly, GlaxoSmithKline, Novartis, Pfizer, Procter \& Gamble, sanofi-aventis, Roche, and Wyeth. Consultant and/or on speaker boards or scientific boards for Amgen Inc., Eli Lilly, Novartis, Roche, GlaxoSmithKline, and Wyeth. Direct stock shareholder of Teva and Procter \& Gamble.

ML Geller, B Ding, E Rockabrand, and RB Wagman: Employees and shareholders of Amgen Inc.

MA Bolognese: Speaker for Amgen Inc., Astra Zeneca, Eli Lilly, Novartis, and GlaxoSmithKline. Research support from Amgen Inc., Eli Lilly, Merck, Roche, Procter \& Gamble, and Takeda. Speaker for Astra-Zeneca, Eli Lilly, Novartis, Amgen Inc., and GlaxoSmithKline. M Peacock: Research grants from Genzyme and consulting fees or other remuneration from KAI Pharmaceuticals.

RL Weinstein: Research support from Amgen Inc.

PD Miller: Scientific grants from Procter \& Gamble, sanofi-aventis, Roche, Eli Lilly, Merck, Novartis, Takeda, and Amgen Inc. Consultant and/or on speaker boards or advisory or scientific boards for Procter \& Gamble, sanofi-aventis, Merck, Eli Lilly, Amgen Inc., Novartis, Roche, and GlaxoSmithKline.

Open Access This article is distributed under the terms of the Creative Commons Attribution Noncommercial License which permits any noncommercial use, distribution, and reproduction in any medium, provided the original author(s) and the source are credited.

\section{References}

1. Burgess TL, Qian Y, Kaufman S, Ring BD, Van G, Capparelli C, Kelley M, Hsu H, Boyle WJ, Dunstan CR, Hu S, Lacey DL (1999) The ligand for osteoprotegerin (OPGL) directly activates mature osteoclasts. J Cell Biol 145:527-538

2. Lacey DL, Tan HL, Lu J, Kaufman S, Van G, Qiu W, Rattan A, Scully S, Fletcher F, Juan T, Kelley M, Burgess TL, Boyle WJ, Polverino AJ (2000) Osteoprotegerin ligand modulates murine osteoclast survival in vitro and in vivo. Am J Pathol $157: 435-448$

3. Lacey DL, Timms E, Tan HL, Kelley MJ, Dunstan CR, Burgess T, Elliott R, Colombero A, Elliott G, Scully S, Hsu H, Sullivan J, Hawkins N, Davy E, Capparelli C, Eli A, Qian YX, Kaufman S, Sarosi I, Shalhoub V, Senaldi G, Guo J, Delaney J, Boyle WJ (1998) Osteoprotegerin ligand is a cytokine that regulates osteoclast differentiation and activation. Cell 93:165-176

4. Udagawa N, Takahashi N, Yasuda H, Mizuno A, Itoh K, Ueno Y, Shinki T, Gillespie MT, Martin TJ, Higashio K, Suda $\mathrm{T}$ (2000) Osteoprotegerin produced by osteoblasts is an important regulator in osteoclast development and function. Endocrinology 141:3478-3484

5. Yasuda H, Shima N, Nakagawa N, Yamaguchi K, Kinosaki M, Mochizuki S, Tomoyasu A, Yano K, Goto M, Murakami A, Tsuda E, Morinaga T, Higashio K, Udagawa N, Takahashi N, Suda T (1998) Osteoclast differentiation factor is a ligand for osteoprotegerin/osteoclastogenesis-inhibitory factor and is identical to TRANCE/RANKL. Proc Natl Acad Sci U S A 95:3597-3602

6. Boyle WJ, Simonet WS, Lacey DL (2003) Osteoclast differentiation and activation. Nature 423:337-342 
7. D'Amelio P, Grimaldi A, Di Bella S, Brianza SZ, Cristofaro MA, Tamone C, Giribaldi G, Ulliers D, Pescarmona GP, Isaia G (2008) Estrogen deficiency increases osteoclastogenesis up-regulating $\mathrm{T}$ cells activity: a key mechanism in osteoporosis. Bone 43:92-100

8. Eghbali-Fatourechi G, Khosla S, Sanyal A, Boyle WJ, Lacey DL, Riggs BL (2003) Role of RANK ligand in mediating increased bone resorption in early postmenopausal women. J Clin Invest 111:1221-1230

9. Kostenuik PJ, Nguyen HQ, McCabe J, Warmington KS, Kurahara C, Sun N, Chen C, Li L, Cattley RC, Van G, Scully S, Elliott R, Grisanti M, Morony S, Tan HL, Asuncion F, Li X, Ominsky MS, Stolina M, Dwyer D, Dougall WC, Hawkins N, Boyle WJ, Simonet WS, Sullivan JK (2009) Denosumab, a fully human monoclonal antibody to RANKL, inhibits bone resorption and increases BMD in knock-in mice that express chimeric (murine/ human) RANKL. J Bone Miner Res 24:182-195

10. Lewiecki EM, Miller PD, McClung MR, Cohen SB, Bolognese MA, Liu Y, Wang A, Siddhanti S, Fitzpatrick LA (2007) Two-year treatment with denosumab (AMG 162) in a randomized phase 2 study of postmenopausal women with low bone mineral density. $\mathrm{J}$ Bone Miner Res 22:1832-1841

11. McClung MR, Lewiecki EM, Cohen SB, Bolognese MA, Woodson GC, Moffett AH, Peacock M, Miller PD, Lederman SN, Chesnut CH, Lain D, Kivitz AJ, Holloway DL, Zhang C, Peterson MC, Bekker PJ (2006) Denosumab in postmenopausal women with low bone mineral density. N Engl J Med 354:821-831

12. Miller PD, Bolognese MA, Lewiecki EM, McClung MR, Ding B, Austin M, Liu Y, San Martin J, Amg Bone Loss Study G (2008) Effect of denosumab on bone density and turnover in postmenopausal women with low bone mass after long-term continued, discontinued, and restarting of therapy: a randomized blinded phase 2 clinical trial. Bone 43:222-229

13. Miller PD, Wagman RB, Peacock M, Lewiecki EM, Bolognese MA, Weinstein RL, Ding B, San Martin J, McClung MR (2011) Effect of denosumab on bone mineral density and biochemical markers of bone turnover: six-year results of a phase 2 clinical trial. J Clin Endocrinol Metab 96:394-402

14. Cummings SR, San Martin J, McClung MR, Siris ES, Eastell R, Reid IR, Delmas P, Zoog HB, Austin M, Wang A, Kutilek S, Adami S, Zanchetta J, Libanati C, Siddhanti S, Christiansen C (2009) Denosumab for prevention of fractures in postmenopausal women with osteoporosis. N Engl J Med 361:756-765

15. Bone HG, Hosking D, Devogelaer JP, Tucci JR, Emkey RD, Tonino RP, Rodriguez-Portales JA, Downs RW, Gupta J, Santora AC, Liberman UA (2004) Ten years' experience with alendronate for osteoporosis in postmenopausal women. N Engl J Med 350:1189-1199

16. Mellstrom DD, Sorensen OH, Goemaere S, Roux C, Johnson TD, Chines AA (2004) Seven years of treatment with risedronate in women with postmenopausal osteoporosis. Calcif Tissue Int 75:462-468

17. Papapoulos S, Chapurlat R, Libanati C, Brandi M, Brown J, Czerwinski E, Krieg MA, Man Z, Mellstrom D, Radominski S, Reginster JY, Resch H, Roman J, Roux C, Vittinghoff E, Austin M, Daizadeh N, Bradley M, Grauer A, Cummings S, Bone H (2011) Five years of denosumab exposure in women with postmenopausal osteoporosis: results from the first two years of the FREEDOM extension. J Bone Miner Res 27:694-701

18. Brown JP, Prince RL, Deal C, Recker RR, Kiel DP, de Gregorio LH, Hadji P, Hofbauer LC, Alvaro-Gracia JM, Wang H, Austin M, Wagman RB, Newmark R, Libanati C, San Martin J, Bone HG (2009) Comparison of the effect of denosumab and alendronate on BMD and biochemical markers of bone turnover in postmenopausal women with low bone mass: a randomized, blinded, phase 3 trial. J Bone Miner Res 24:153-161

19. Genant HK, Engelke K, Hanley DA, Brown JP, Omizo M, Bone HG, Kivitz AJ, Fuerst T, Wang H, Austin M, Libanati C (2010) Denosumab improves density and strength parameters as measured by QCT of the radius in postmenopausal women with low bone mineral density. Bone 47:131-139

20. Seeman E, Delmas PD, Hanley DA, Sellmeyer D, Cheung AM, Shane E, Kearns A, Thomas T, Boyd SK, Boutroy S, Bogado C, Majumdar S, Fan M, Libanati C, Zanchetta J (2010) Microarchitectural deterioration of cortical and trabecular bone: differing effects of denosumab and alendronate. J Bone Miner Res 25:1886-1894

21. Ominsky MS, Jolette J, Smith SY, Vlasseros F, Samadfam R, Kostenuik PJ (2008) Transition from alendronate to denosumab resulted in further reductions in local and systemic bone turnover parameters and reduced cortical porosity in ovariectomized cynomolgus monkeys [abstract 1216]. J Bone Miner Res 23(suppl S1):S61

22. Macdonald HM, Nishiyama KK, Hanley DA, Boyd SK (2011) Changes in trabecular and cortical bone microarchitecture at peripheral sites associated with 18 months of teriparatide therapy in postmenopausal women with osteoporosis. Osteoporos Int 22:357-362

23. Sato M, Westmore M, Ma YL, Schmidt A, Zeng QQ, Glass EV, Vahle J, Brommage R, Jerome CP, Turner CH (2004) Teriparatide [PTH(1-34)] strengthens the proximal femur of ovariectomized nonhuman primates despite increasing porosity. J Bone Miner Res 19:623-629 